\title{
Production of Bio-Electricity Through Bacterial Catalysis in Microbial Fuel Cell Running on Garri-Processing Wastewater
}

\author{
${ }^{\star 1}$ Oyiwona, G. E., ${ }^{2}$ Ogbonna, J. and ${ }^{2}$ Anyanwu, C. U.
}

${ }^{1}$ Department of Science Laboratory Technology, Benue State Polytechnic, Ugbokolo, Benue State.

${ }^{2}$ Department of Microbiology, Faculty of Biological Sciences, University of Nigeria, Nsukka, Nigeria.

*Corresponding Author: godwinloveth1@gmail.com; +234-8061507504

\begin{abstract}
Two H-type dual-chambered glucose-fed MFC reactors, each with a working volume of $250 \mathrm{ml}$ designated as GPWW (enriched from garri wastewater) and the other as DWW (enriched from domestic wastewater) were constructed under same conditions and the anodes were continuously fed with synthetic medium (SM) at a flow rate of $0.7 \mathrm{ml} \mathrm{min} \mathbf{~}^{-1}$. An average power density (Pd) of $1.5 \pm 1.39 \mathrm{~W} / \mathrm{m}^{3}$ for GPWW and $0.6 \pm 0.6 \mathrm{~W} / \mathrm{m}^{3}$ for $D W W$ was observed in 150 days of operation. The peak biomass density for DWW was significantly $(P<0.05 T$-test) higher than that of GPWW by a factor of $2(8.99 \mathrm{mg}$ versus $3.4 \mathrm{BSA}$ /total anode respectively) on day 120 suggesting that more biomass was formed on DWW than GPWW reactor. This indicates that exo-electrogens in DWW reactor directed more of electron flow to cell synthesis rather than to current. The archaea footprints detected on the anodes were limiting factors in current generation. One vital milestone in this study is the discovery of the potential of garriprocessing wastewater as a veritable substrate in microbial fuel cell technology.
\end{abstract}

Key words: Biomass density, Dissimilatory metal reducing bacteria, Current density, Microbial fuel cell, Power density.

\section{Introduction}

Microbial fuel cells (MFCs) are new form of renewable energy technology that generates bioelectricity from wastes (Greenman et al. 2015). In our energy-based society, the value of any energy-rich matter is increasing, thus the high organic load in wastewaters is no longer seen as a waste but a valuable energy resource (Marthuriya and Sharma, 2009). Finding a way to exploit these biological substrates degradation for electricity generation is the driving force for the development of microbial fuel cells. Many researches are currently focused on the use of MFC technology for many applications, such as wastewater treatment (Zhang et al., 2012). Traditional wastewater treatment plants generate a tremendous quantity of sludge. Such dry sludge cannot be disposed before appropriate treatments (Burke et al., 2003). However, sludge treatments are expensive; therefore, reducing sludge treatment costs can significantly reduce the total costs for wastewater treatment (Logan et al. 2013). Sludge collected from wastewater treatment plants often contains high levels of organics (Ting and Lee, 2007). Microbial fuel cell (MFC) can be applied to convert organic matters in sewage sludge to electricity under ambient temperature, normal pressure, and neutral $\mathrm{pH}$
(Zhang et al. 2012). With the discovery of dissimilatory metal reducing bacteria (DMRB) came a new way to employ and study MFC systems. Dissimilatory metal reducing bacteria can transfer electrons directly to solid substrates by way of outer membrane proteins (cytochromes) that are up-regulated under anaerobic conditions (Wan et al. 2004).

Glucose is a basic unit of organic compounds, most sugars and carbohydrates that abundantly exist in wastewater, such as garri wastewater, are composed of glucose molecules (Kim et al. 2011).

In attempts to produce electricity efficiently from organic substrates, researchers have been focusing their studies on crucial factors influencing comprehensive microbial fuel cell performance (Kim et al. 2008; Logan et al. 2006). Here, we show that the organic component of the environmental pollutant, garri-processing wastewater from Nigeria can be a potential electron donor in bioelectricity production in MFC.

\section{Materials and Methods}

Reactor Construction, Configuration and Operation: Dual-chambered MFCs were constructed by joining $200 \mathrm{ml}$ capacity media bottles with glass tubes clamped between the 
flattened ends of the glass tubes(inner diameter1.6) fitted with rubber gaskets between which a proton exchange membrane (PEM; Nafion ${ }^{\circledR}$ 117, Dupond Co., De, USA) was placed. The top of the bottles were pierced with copper wires. The electrodes in the both chambers were graphite-rod $\left(18 \mathrm{~cm}^{2}\right.$ area) obtained from $1.5 \mathrm{~V}$ Tiger Head batteries. Air-saturated tap water was fed into the cathode compartment in order to supply the oxygen needed for the electrochemical reaction. The two MFCs where operated in continuous mode for 150 days. The GPWW inoculum was obtained from garri production site while the DWW inoculum was obtained from a household wastewater all in Ugbokolo, Benue State, Nigeria. The anodic compartments were continuously fed with glucose synthetic medium(GSM) with composition (per litre):Glucose: $10 \mathrm{mM}$; $\mathrm{K}_{2} \mathrm{HPO}_{4}: 100 \mathrm{Mm} \quad ; \mathrm{KH}_{2} \mathrm{PO}_{4}: \quad 20 \mathrm{mM}$; $(\mathrm{NH} 4) \mathrm{SO}_{4}: 0.2 \mathrm{mM} ; \quad \mathrm{MgCl}_{2} .6 \mathrm{H}_{2} \mathrm{O}: 0.5 \mathrm{mM}$; $\mathrm{CaCl}_{2}: 0.5 \mathrm{mM}$; Vitamins: $100 \mu \mathrm{l}$; Trace elements: $100 \mu \mathrm{l}$, at a flow rate of $0.7 \mathrm{ml} \mathrm{min}^{-1}$ with the help of peristaltic pump. The operating room temperature throughout the experiment was $30-35^{\circ} \mathrm{C}$. The external resistance for the two reactors was fixed at $50 \Omega$ during the entire operation. Figure1 shows the schematic diagram of the $\mathrm{H}$-type reactor used.

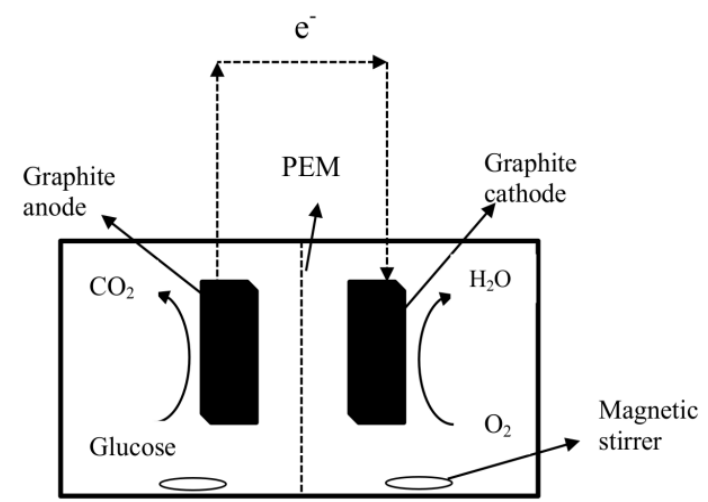

Fig. 1: Two chamber H-type reactor

Sample collection: Garri-processing and domestic wastewater samples were collected from garri-processing site and a domestic household in Ugbokolo and transported to the laboratory. Samples were transported in plastic bottles to the laboratory and stored in a refrigerant prior to use same day. A total of 3 (three) samples were brought to the laboratory.

Start-up of MFC operation in both reactors: The MFC anode chambers for GPWW and DWW were inoculated with $20 \% \mathrm{v} / \mathrm{v}$ of the garri-wastewater and domestic wastewater respectively as substrate and inoculum to start-up the MFC operation. The settled wastewater were pipetted out using a pipette controller and centrifuged at 5000rpm for 5 minutes. The pellets were re-suspended in GSM and stored at $4^{\circ} \mathrm{C}$ for use as inoculum. Prior to inoculation the pellets was washed thrice in 1xPBS and enriched in GSM under anaerobic conditions. The reactors were operated in a continuous operation for 150 days.

\section{Electro-chemical analysis}

Data collection: The voltage across an external resistor of $100 \mathrm{ohm}$ was recorded every $1 \mathrm{hr}$ for 150 days using a voltmeter.

Power output: Voltage (V), Power density $(\mathrm{Pd})$ and Current density (Cd) values were acquired.

Voltage was converted to power density $\mathrm{P}$ $\left(\mathrm{W} / \mathrm{m}^{3}\right)$ according to $\mathrm{P}=\mathrm{IV} / \mathrm{a}$

Where: $\mathrm{I}=$ Current $(\mathrm{A}), \mathrm{V}=$ Voltage $(\mathrm{V})$, $a=$ Anode volume $\left(\mathrm{m}^{3}\right), \mathrm{Cd}=$ Current density (A)/a.

pH: The $\mathrm{pH}$ of the effluent and influent anodic media were monitored by the use of a calibrated laboratory $\mathrm{pH}$ meter (Weilheim, Germany).

Fe (III)-reducing capability: In order to further investigate the electrochemical activity of the anode biofilms, SM was used to isolate pure colonies from the anode on solid agar. Glucose $(5 \mathrm{mM})$ was used as sole electron donor. The synthetic medium (SM) contained $10 \mathrm{mM}$ glucose as the electron donor and 20 $\mathrm{mM}$ ferric citrate as the electron sink. Electrogenic bacteria were isolated from the anode of GPWW on day 20 . A piece $\left(1 \mathrm{~cm}^{2}\right)$ of anode electrode, graphite felt, was transferred to a pressure tube containing $10 \mathrm{~mL}$ sterile $\mathrm{SM}$. The samples were vortexed for $10 \mathrm{~min}$ to separate microbial cells from the electrode. The suspension was serially diluted in 10-folds to an end point of $10^{-7}$ in tubes and then plated on solid SM containing $5 \mathrm{mM}$ glucose and $20 \mathrm{mM}$ ferric citrate as electron donor and acceptor respectively. The plates were incubated at $30^{\circ} \mathrm{C}$ for $72 \mathrm{hrs}$ in an anoxic jar under anoxic conditions. Fe (III)-reducing colonies were easily recognized as they formed halos around them on the plate, due to $\mathrm{Fe}$ (III) reduction.

Biomass density measurement: In order to determine the total microbial density on the attached cells on the anode surface, protein was extracted from the anode surface using 
the Bio-Rad® protein assay protocol (BioRad( ${ }^{2}$ Laboratories, California, USA) according to manufacturer's instructions. Bovine serum albumin (BSA) was also used as the protein standard from which a calibration curve was constructed to determine the concentration of proteins in the samples. Investigation of the microbial community on the anode

DNA extraction: DNA used for all genomic experiments in this study was obtained from the anodic biomass in the reactors. The samples were collected on specified dates. DNA extractions from samples were performed simultaneously under same conditions by using PowerSoil ${ }^{\circledR}$ DNA Isolation Kit (Mo Bio Laboratories Inc. USA) following manufacturer's instructions.

Polymerase chain reaction (PCR) screening: Bacterial 16S rRNA and archaeal mcrA genes

Partial 16S rRNA genes were amplified with the universal bacteria primers Bac331f and 797r for dormain bacteria. The list of archaea primer sets used were MBAC $f$, MBAC $r$; MMICf, MMICr; MSaet $f$, MSaetr; MSarc f, Msarc r. Amplification was carried out in a $25 \mu \mathrm{l}$ reaction volume of genomic DNA, 10x Ex-taq buffer, $3 \mathrm{mM} \mathrm{MgCl}$, $10 \mathrm{pmol}$ of each primer, $0.6 \mathrm{mM}$ of each dNTP and $1.25 \mathrm{U}$ of Taq DNA polymerase (Invitrogen, Carlsbad, CA, USA), which allows for hot-start PCR. All of the PCR reactions were conducted using a Veriti 96 well Thermocycler (Applied Biosystems, CA., USA.). Samples were loaded into a $1.5 \%$ agarose gel and PCR products were separated on the gel. The bands were visualized using SYBR $^{\circledR}$ Safe DNA gel stain (Invitrogen, Burlington, ON), in Safe Imager 2.0 (Invitrogen Canada, Burlington, ON) and the product sizes were determined by comparison with 100 base pair molecular ruler (New England Biolab. Pickering, ON).

Statistical analysis: Data generated were analyzed statistically, using the Student's tTest. All experiments were carried out in triplicates. Descriptive statistics was used to present data.

\section{Results}

\section{Reactor performance}

Power output

About 7 days after start-up the two reactors used for enrichment of anodes demonstrated reproducible cycles of power production with an average power density of $1.5 \pm 1.39 \mathrm{~W} / \mathrm{m}^{3}$ for SLG and $0.6 \pm 0.6 \mathrm{~W} / \mathrm{m}^{3}$ for GPWW in 150 days of operation (Fig. 2). There was a significant $(p<0.05)$ difference in power density evolution between GPWW and DWW. GPWW produced its peak power density of $3.22 \mathrm{~W} / \mathrm{m}^{3}$ on days 96 while DWW had its peak of $1.69 \mathrm{~W} / \mathrm{m}^{3}$ on day 110 .

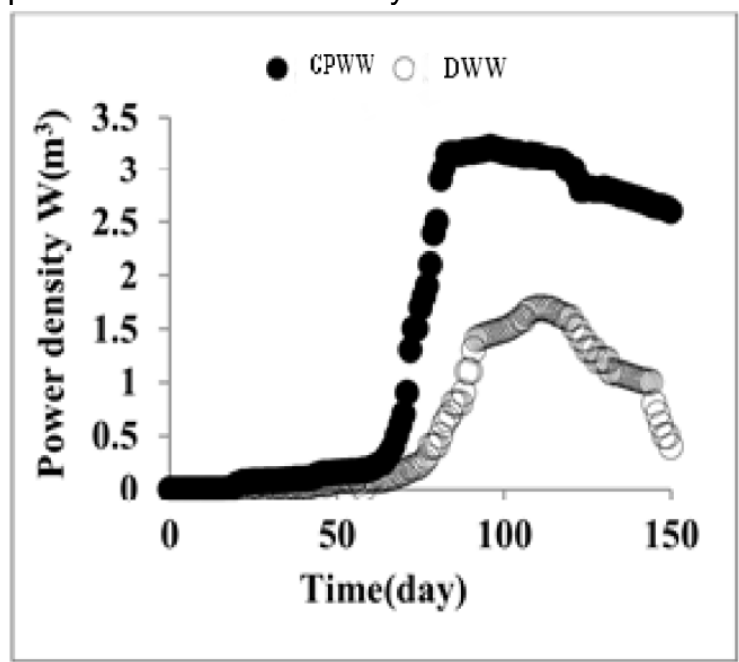

Fig. 2: Time-course-evolution of power density

pH

The influent and effluent $\mathrm{pHs}$ of the reactors were maintained at $7.08 \pm 0.08$ and $6.80 \pm 0.07$ for GPWW and $7.08 \pm 0.08$ and $6.83 \pm 0.08$ for DWW respectively during the run period (Fig. $3)$. This was achieved by $100 \mathrm{mM}$ phosphate buffer.

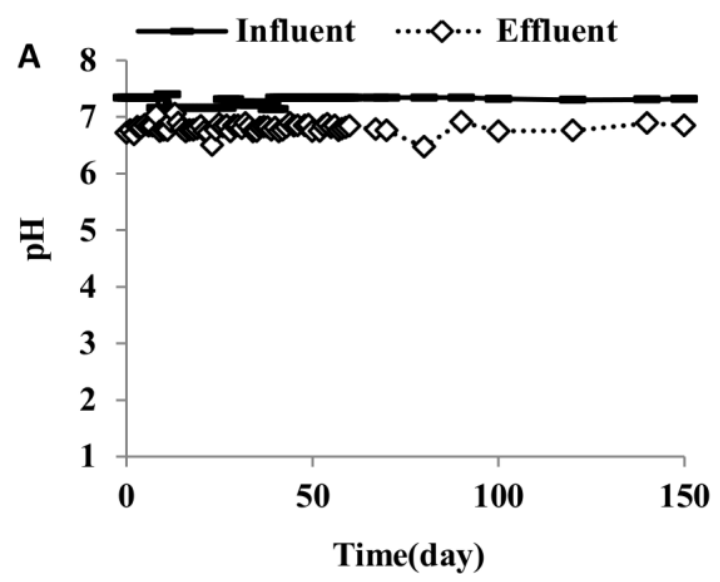




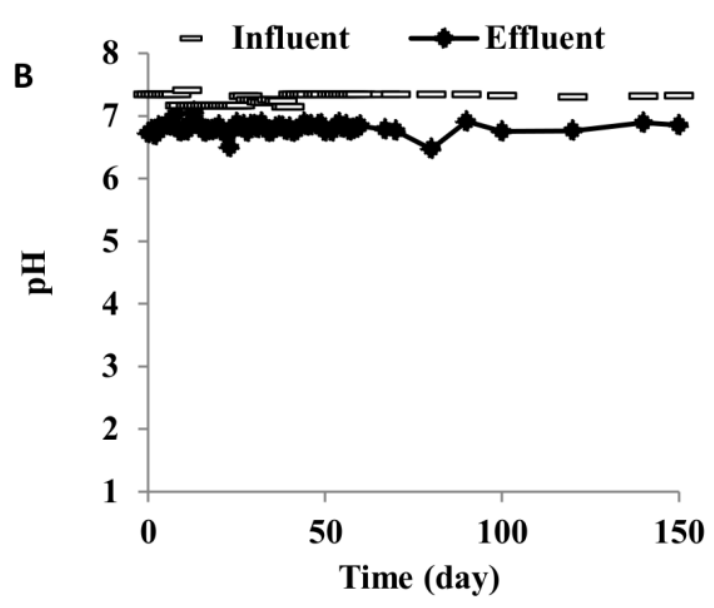

Fig. 3: Time-course of medium $\mathrm{pH}$ in days of operation

${ }^{\mathrm{a} G P W W}$, bDW

\section{Biomass density}

Biomass density from protein assay was monitored in the reactors up to day 120 (Fig. 4). The results of the assay indicate that the peak biomass density for DWW was significantly $(P<0.05$ Student's $T$-test $)$ higher than that of GPWW by a factor of $2(8.99 \mathrm{mg}$ versus 3.4 BSA/total anode respectively) on day 120 . Therefore, more biomass was formed on DWW than GPWW reactors.

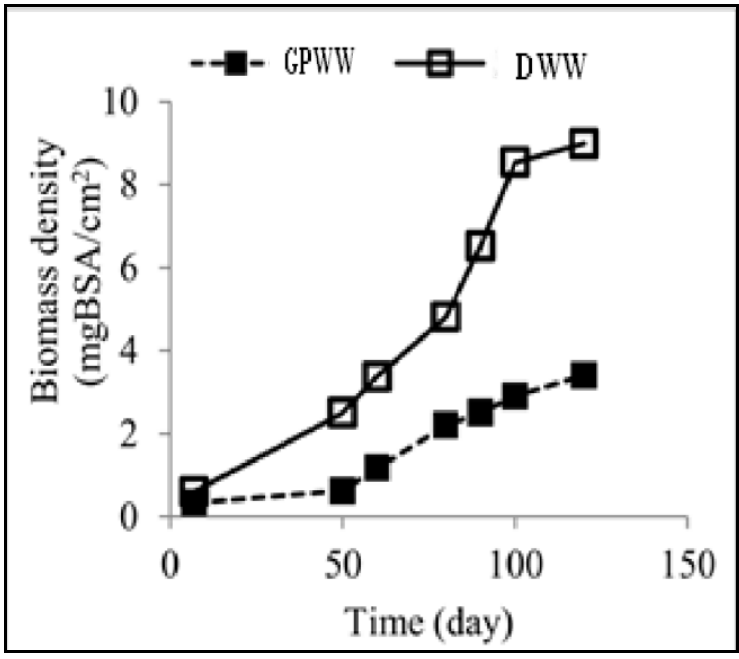

Fig. 4: Time-course of biomass density of attached biofilms

\section{Effect of biomass density on current generation}

The result of the average current density over time based on the evolution of biomass on the anode (Table 1) indicates that current increases linearly with biomass density up to day 80. In GPWW, there was a significant decline $(P<0.05)$ in current density values on days $80-120(16.3 \pm 1.5$ to $8.4 \pm 0.56)$ while the current density values for DWW within same periods were not significant $(4.2 \pm 1.2$ to $4.1 \pm 1.45)$. Values were determined on days 50,80 and $120(n=2)$.

Table 1. Effect of biomass concentration on current generation

\begin{tabular}{lllll}
\hline Day & $\begin{array}{l}\text { GPww } \\
\text { Biomass } \\
\left.\text { density(mgBSA/cm }{ }^{2}\right)\end{array}$ & $\mathbf{C d}\left(\mathbf{A} / \mathbf{m}^{3}\right)$ & $\begin{array}{l}\text { Dww } \\
\text { Biomass } \\
\text { density }\left(\mathbf{m g B S A} / \mathbf{c m}^{2}\right)\end{array}$ & $\mathbf{C d}\left(\mathbf{A} / \mathbf{m}^{3}\right)$ \\
\hline 50 & 0.62 & $5.3 \pm 2.1$ & 2.5 & $3.8 \pm 1.22$ \\
80 & 2.2 & $16.3 \pm 1.5$ & 4.81 & $4.2 \pm 1.2$ \\
120 & 3.4 & $8.4 \pm 0.56$ & 8.99 & $4.1 \pm 1.45$ \\
\hline
\end{tabular}

Investigation of Fe (III) reducing capability of anodic isolates

The results culture of some isolates from GPWW and DWW (Fig. 5) shows clear halos of $\mathrm{Fe}$ (III) reduction around the colonies. The halos around GPWW appeared to be more prominent than that of DWW. 

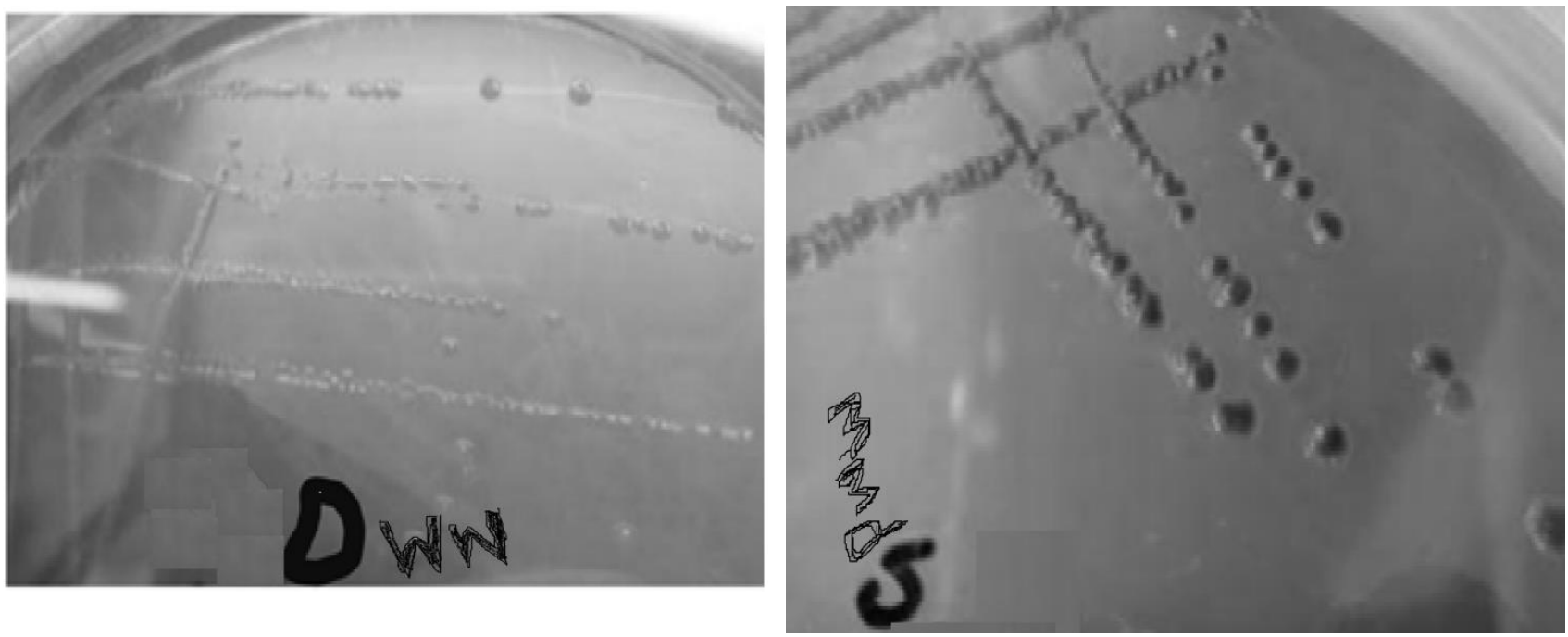

Fig.5. Fe(III)-reducing capability

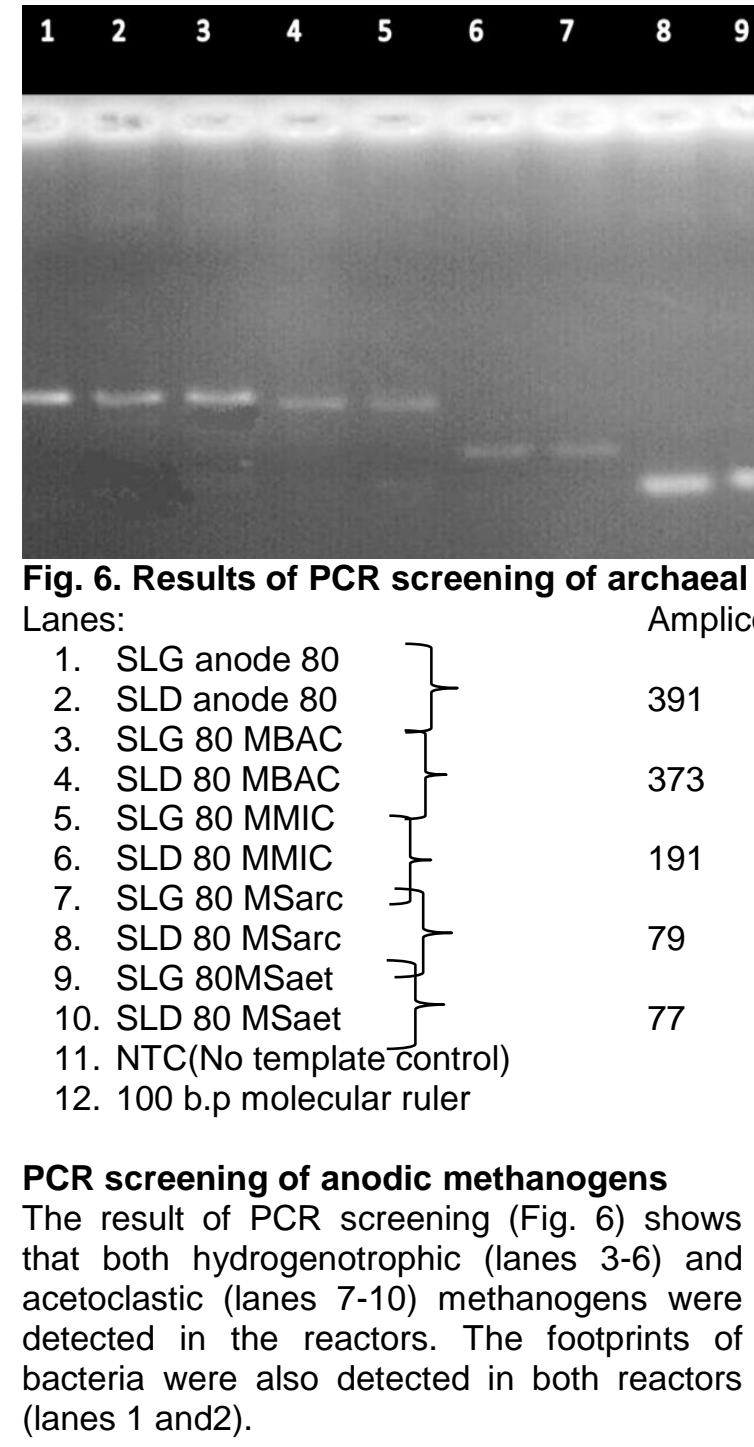

\section{Discussion}

The significantly $(p<0.05)$ higher peak power density in GPWW compared to DWW could be attributed to the presence of $e^{-}$-sinks other than the anode and moribund biomass, in DWW which diverts electrons meant for the anode resulting, in lower current density and voltage decrease. This is consistent the findings of (Torres et al. 2007) that electron 
sinks other than the anode of MFC results in low Coulombic efficiency (CE) as a result of the release of gaseous fermentative products such as $\mathrm{CH}_{4}$ and $\mathrm{H}_{2}$ generated at more negative (lower) anode potential (Wang et al. 2011).

The significant difference in current density (Cd) evolution between GPWW and DWW could be explained by the differences in biomass densities. An average total biomass density of $2.1 \mathrm{mgBSA} \pm 1.3 / \mathrm{cm}^{2}$ and $5.4 \mathrm{mgBSA} \pm 3.2$ accumulated at the anode of GPWW and DWW respectively.

The results suggest that exo-electrogens in DWW reactor directed more of electron flow to cell synthesis rather than to current. This is consistent with leropolous et al., (2010), that increase in anodic biomass brings with it an increase in non-conductive cellular components that will create a resistive coating which enhances mass transfer resistance. Reguera et al., (2006) earlier reported that a direct correlation exist between the amount of anode biomass and current production.

The $\mathrm{pH}$ variations were maintained between 6.72-6.82 in the reactors throughout the operation. The $\mathrm{pH}$ decreased to 6.33 and 6.5 for GPWW and DWW respectively on days 23 and 22 as a result of accumulation of VFAs (Hu et al., 2007).

\section{Conclusion}

The lower biomass density on the anode of GPWW reduced a mass transfer resistance which helped in the higher average power density of $1.55 \mathrm{~W} / \mathrm{m}^{3}$ compared to average power density of $0.65 \mathrm{~W} / \mathrm{m}^{3}$ recorded for DWW. The biomass may have interfered with the ability of electrogenic bacteria to make direct contact with the anode and accentuated the internal and charge transfer resistance.

\section{Conflict of Interest}

There is no conflict of interest regarding the manuscript.

\section{References}

Burke, S., Heathwaite, I., Quinn, P., Merret, S., Whitehead, P., Preddy ,N., Lerner, D. and Saul, A. (2003). Strategic management of non-point source pollution from sewage sludge. Water Science and Technology, 47(8): 305-310.

Greenman, J., You, J., Melhuish, C. and leropoulos, I. (2015). Electricity generation and struvite recovery from human urine using microbial fuel cells. $J$ Chem Technol Biotechnol. doi:10. 1002/jctb.4617

Hu, B. and Chen, S. L. (2007). Pretreatment of methanogenic granules for immobilized hydrogen fermentation. Journal of Hydrogen Energy, 32: 3266-3273.

leropoulos,I., Winfred, J., Greenman, J.(2010). Effects of flow-rate, inoculum and time on the internal resistance of microbial fuel cells. Bioresource Technology, 101:35203525.

Kim, I. S., Chae, K. J., Verstraete, W. and Choi, M. J. (2008). Microbial fuel cells: Recent advances. Bacterial communities and applications beyond electricity generation. Environmental Engineering Resource, 13: 51-65.

Kim, I. S., Kim, K. Y., Chae, K. J., Choi, M. J., Ajayi, F. F., Jang. A. M. and Kim, C-W. (2011). Enhanced coulombic efficiency in glucose-fed microbial fuel cells by reducing metabolite electron losses using dualanode electrodes. Bioresource Technology, 102: 4144-4149.

Logan, B. E., Hamelers, B., Rozendal, R., Schroder, U., Keller, J., Freguia, S., Aelterman, P., Verstraete, W. and Rabaey, K. (2006). Microbial fuel cells: Methodology and technology. Environmental Science and Technology, 40: 5181-5192.

Logan,B.E.,Yuepu, P., Ren, L. and Yang, F. (2013). Electricity generation from fermented primary sludge using singlechamber air-cathode microbial fuel cells. Bioresource Technology, 128: 784-787.

Mathuriya, A. S. and Sharma, V. N. (2009). Bioelectricity production from various wastewaters through microbial fuel cell technology. Journal of Biochemical Technology, 2(1): 133-137.

Reguera, G., Nevin, K.P., Nicoll, J.S., Covalla, S.F., Woodard, T. L., and Lovley, D. R. (2006). Biofilm and nanowire production leads to increased current in Geobacter sulfurreducens fuel cells. Applied and Environmental Microbiology, 72: 73457348.

Ting, C. H. and Lee, D. J. (2007). Production of hydrogen and methane from wastewater 
sludge using anaerobic fermentation. Internal Journal of Hydrogen Energy, 32(6): 677-682.

Torres, C. I., Kato, M. A. and Rittmann, B. E. (2007). Kinetics of consumption of fermentable products by anode-respiring bacteria. Applied Microbiology and Biotechnology, 77:689-697.

Wan, X. F. and VerBerkmoes, N.C. (2004). Transcriptomic and Proteomic Characterization of the Fur Modulon in the Metal-Reducing Bacterium Shewanella oneidensis. Journal of Bacteriology, 186(24): 8385-8400.

Wang, X., Yujie, F., Ren, N., Lee, H. and Liu, J. (2011). Performance of a batch twochambered microbial fuel cell operated at different anode potentials. Willeyonlinelibrary.com. Doi 10.

Zhang, G., Zhao, Q., Jiao, Y, Wang, K., Lee, D. J., Ren, N. (2012). Scalable microbial fuel cell (MFC) stack for continuous real wastewater treatment. Bioresource Technology, 106: 82-88. 1002/jctb.2258. 